\title{
Relationship between Bone Mineral Density and Parity in Women of Reproductive Age Group
}

\author{
${ }^{1}$ Fatema Jesmin, ${ }^{2}$ Fatima Begum, ${ }^{2} \mathrm{C}$ A H M Enamullah and ${ }^{2}$ Faridul Alam \\ ${ }^{1}$ Department of Radiology \& Imaging, Dhaka National Medical Institute \& Hospital, Dhaka- \\ ${ }^{2}$ National Institute of Nuclear Medicine and Allied Sciences, BAEC, Dhaka, Bangladesh. \\ Correspondence Address : Fatema Jesmin, Consultant Sonologist, Department of Radiology \& Imaging, \\ Dhaka National Medical Institute \& Hospital, Johnson Road Dhaka, e-mail: fatema_jesmin@yahoo.com.
}

\begin{abstract}
Objective: The objective of this study was to assess the relationship between Bone Mineral Density (BMD) and parity in women of reproductive age group.

Materials and methods: A cross sectional analytical study was carried out where the study population was women of reproductive age group (15 to 49 years of age). A total of 180 women were included as study subjects and the sampling technique was non random sampling. The study population was selected from healthy women of reproductive age group. Data about age, height, weight and history of parity were taken. BMD was measured by DEXA. Then relationship between BMD and parity were analysed.

Results: In this study, a large number, 79 (43.9\%) of participants were in age group of 29-38 years with mean \pm SD 35.46 \pm 6.75 years. Association between BMD and age of the study subjects represented that values of BMD decreased with increasing age $(P<0.05)$. Bivariate analysis between BMD and parity revealed that values of BMD at lumbar spine and femur were associated with parity and it was also showed that the BMD of nulliparous women and one-to-two parity groups were significantly higher than multiparous $(\geq 3$ parity) women $(P<0.05)$.

Conclusion: From overall analysis of this study it can be concluded that BMD at lumbar spine and femur in women of reproductive age group was negatively associated with number of parity.

Key words: Bone Mineral Density (BMD), Dual Energy X-ray Absorptiometry (DEXA), Statistical Package for Social Sciences (SPSS)
\end{abstract}

\section{INTRODUCTION}

Bone mineral density (BMD) is a medical term which refers to the amount of mineral matter per square centimeters of bones. BMD is used in clinical medicine as an indirect indicator of osteoporosis as well as fracture risk (1). Parity is defined as the number of previous pregnancies of greater than 28 weeks gestation and is considered both a measure of a woman's fertility status as well as her reproductive success. Parity is commonly classified in different levels as nulliparity, primipara, multiparity, grand multiparity and great grand multiparity (2). Osteoporosis is an emerging public health problem in developing countries (3).
BMD is one of the best predictors of osteoporotic bone fractures. Therefore, to prevent fracture, it is very important to identify risk factors for bone mineral loss. Calcium dynamics is one of the most important determinants of BMD. During pregnancy, appropriate mineralization of the fetal skeleton requires approximately $30 \mathrm{gm}$ of calcium from maternal sources. Moreover, abundant calcium is lost from the mother during lactation as breast milk contains calcium in large quantities. These phenomena suggest that BMD might change during pregnancy and after parturition

(4). This study was carried out to assess the relationship between Bone Mineral Density (BMD) and parity in women of reproductive age group.

\section{MATERIALS AND METHODS}

A cross sectional analytical study was carried out at the National Institute of Nuclear Medicine and Allied Sciences (NINMAS), BSMMU campus, Shahbag, Dhaka and Institute of Nuclear Medicine and Allied Sciences, SSMCH Campus, Mitford, Dhaka over a period of twelve months from January 2012 to December 2012. The study population was women of reproductive age group (15 to 49 years of age). A total of 180 women were included as study subjects where the sampling technique was non random sampling. Healthy women of reproductive age group constituted the study population. These women were not suffering from any systemic diseases and were not on any drugs which could lead to low bone mass. Women with poor socio-economic condition were not included in this 
study. Study subjects were taken from good socioeconomic condition with the intention of including each subjects having similar dietary habit especially about dairy products intake. Data were collected according to formatted data collection sheet by face to face interview. Body weights were measured without shoes and in light clothing's and recorded as kilograms. Body heights were measured without shoes and recorded as centimeters. BMI was expressed as weight in $\mathrm{kg}$ per height in squared meters. Before starting the study procedure an informed written consent form was signed by each study subject. Women of reproductive age group were classified into several groups according to age (group I: $\leq 28$, group II: $29-38$, group III: $\geq 39$ years of age). For measurement of BMD, DEXA scan was performed by Central DEXA (Model: XR-46, Norland) Densitometer. BMD was measured at lumbar vertebrae L2-L4 and femoral neck. Posterior and anterior projections were taken for lumbar spine BMD. Region of interest was L2- L4 vertebra which was analyzed for individual and total vertebrae. The hip scan procedure estimated bone mineral in the femoral neck. Analysis of data from DEXA was computerized and completely automated (5).

Statistical analysis: After collection of data, editing, coding and entry were done manually. The data were analyzed with the help of Computer Software SPSS (Statistical Package for Social Sciences) program, version 18. In SPSS, data were analyzed by two stages. Initially- descriptive statistics such as frequency, percentage, mean, $\mathrm{SD}$, range were calculated to explore the basic characteristics of the study subjects. Thereafter- bivariate analysis such as Fisher's exact test, Pearson's correlation coefficient and Scatter diagram were performed to find out the association between two variables. In each analysis, level of significance was 0.05 and $p$ value $<0.05$ was considered as statistically significant.

\section{RESULTS}

Among 180 women, there were 31 (17.2\%) in group $\leq 28$ years, $79(43.9 \%)$ in group $29-38$ years and 70 (38.9\%) in group 39 and above years. The mean \pm SD was $35.46 \pm 6.75$ years with a range of $19-48$ years (Table 1). At lumbar spine, majority 107 (59.4\%) of women had normal BMD and rest 73 (40.6\%) of them had low BMD. At femoral neck, 90 (50\%) of the study subjects were osteopenic and $27(15 \%)$ were osteoporotic and rest $63(35 \%)$ of them had normal bone mass (Figure $1 \& 2$ ). Association between age group and BMD at lumbar spine and femur was presented in Table 2. In case of lumbar spine, majority $27(87.1 \%)$ of study subjects had normal BMD in younger age group ( $\leq 28$ years) and higher percentage 37 (52.9\%) of low BMD was observed in older age group ( $\geq 39$ years). In case of femur, osteopenia and osteoporosis were found in higher percentage $54(77.1 \%)$ in women of 39 years and above. This differences of BMD values between younger and older age group were statistically significant $(\mathrm{P}<0.05)$ (Table 3). Association between BMD and parity among study subjects was shown in (Table 3). At lumbar spine and femur, the percentage of normal bone mass in nulliparous women and oneto-two parity groups were higher than those of the other groups. In case of multiparous women of para 3-4 and para 5 or more, the percentage of low BMD was higher than normal bone mass. These differences were statistically significant $(\mathrm{P}<0.001)$ (Table 3$)$.

Table 1: Distribution of study subjects according to age group $(\mathbf{n}=180)$

\begin{tabular}{ccc}
\hline $\begin{array}{c}\text { Age group (in } \\
\text { years) }\end{array}$ & Frequency (n) & Percent (\%) \\
\hline$\leq 28$ & 31 & 17.2 \\
$29-38$ & 79 & 43.9 \\
$\geq 39$ & 70 & 38.9 \\
\hline Total & 180 & 100.0 \\
\hline
\end{tabular}

$\mathrm{Mean} \pm \mathrm{SD}=35.46 \pm 6.75$ years (Range: $19-48$ years) 


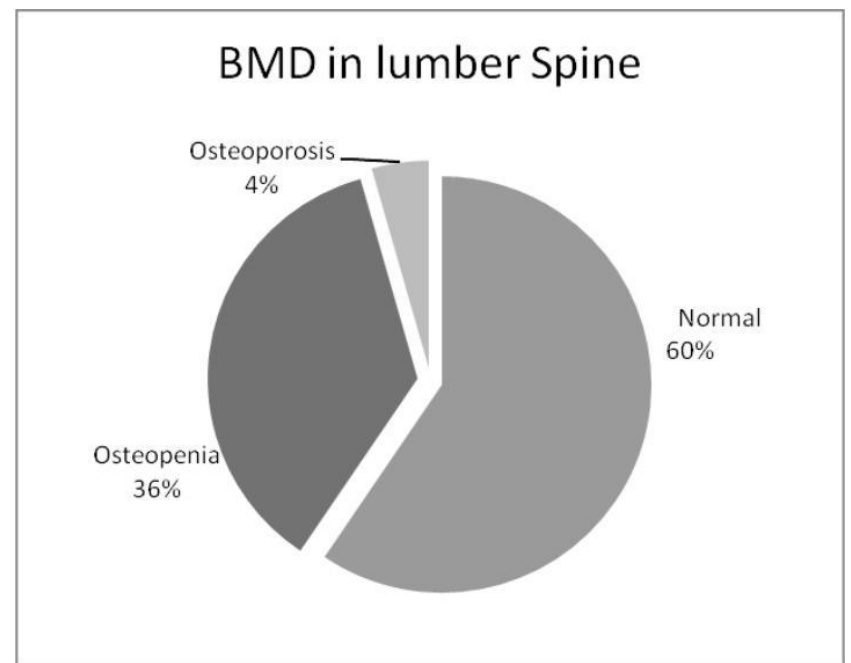

Figure 1: Pie chart showing proportion of women according to BMD values at lumbar spine.

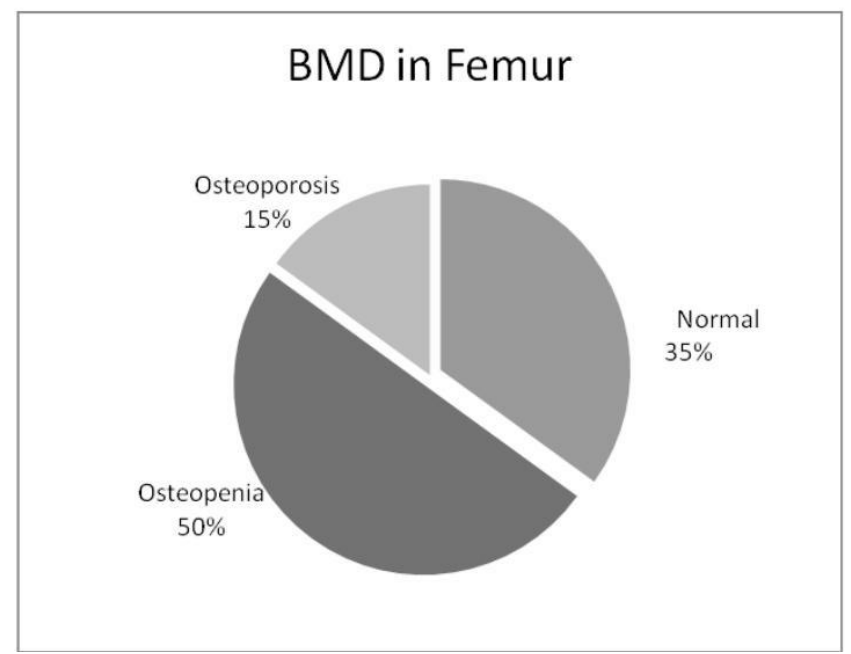

Figure 2: Pie chart showing proportion of study subjects according to BMD values at femur.

Table 2: Association between age group and BMD at lumbar spine and femur

\begin{tabular}{|c|c|c|c|c|c|}
\hline & \multirow{2}{*}{ B.MD } & \multicolumn{3}{|c|}{ Age group } & \multirow{2}{*}{ p-value } \\
\hline & & $\leq 28(\mathrm{yrs})$ & $29-38(y r s)$ & $\geq 39$ (yrs) & \\
\hline \multirow{3}{*}{ Spine } & Normal & $27(87.1)$ & $47(59.5)$ & $33(47.1)$ & \multirow{3}{*}{0.003} \\
\hline & Osteopenia & $4(12.9)$ & $28(35.4)$ & $33(47.1)$ & \\
\hline & Osteoporosis & $0(0)$ & $04(5.1)$ & $04(5.8)$ & \\
\hline \multirow{3}{*}{ Femur } & Normal & $15(48.4)$ & $32(40.5)$ & $16(22.9)$ & \multirow{3}{*}{0.002} \\
\hline & Osteopenia & $16(51.6)$ & $38(48.1)$ & $36(51.4)$ & \\
\hline & Osteoporosis & $0(0)$ & $9(11.4)$ & $18(25.7)$ & \\
\hline
\end{tabular}

Figures in the parentheses indicate corresponding percentages.

$P$ valuc $<0.05$ was considered as significant.
Table 3: Association between BMD and parity among study subjects $(\mathrm{n}=180)$

\begin{tabular}{llccccc}
\hline \multirow{2}{*}{ BMD } & \multicolumn{5}{c}{ Parity } & \\
\cline { 3 - 6 } & & $\mathbf{0}$ & $\mathbf{1 - 2}$ & $\mathbf{3 - 4}$ & $\mathbf{2 5}$ & p-value \\
\hline \multirow{4}{*}{ Spine } & Osteopenia & $7(21.2)$ & $10(17.2)$ & $28(47.5)$ & $20(66.6)$ & $<0.001$ \\
& Osteoporosis & $0(0)$ & $1(1.8)$ & $2(3.4)$ & $5(16.7)$ & \\
\hline \multirow{4}{*}{ Femur } & Normal & $21(63.6)$ & $32(55.2)$ & $9(15.2)$ & $1(3.4)$ & \\
& Osteopenia & $10(30.3)$ & $23(39.6)$ & $44(74.6)$ & $13(43.3)$ & $<0.001$ \\
& Osteoporosis & $2(6.1)$ & $3(5.2)$ & $6(10.2)$ & $16(53.3)$ & \\
\hline
\end{tabular}

Figures in the parentheses indicate corresponding percentages. $\mathrm{P}$ value $<0.05$ was considered as significant.

\section{DISCUSSION}

Osteoporosis is a major public health problem in developing countries (3). The women of reproductive age group are a vulnerable group who are suffering from low bone mass due to various reproductive factors. The reproductive factors causing osteoporosis should be evaluated in this age group. The aim of this study was to evaluate relationship between BMD and parity in women of reproductive age group.

The age range of the present study was 19 to 48 years of age with mean \pm SD was $35.46 \pm 6.75$ years. These findings were consistent with the previous study where study subjects were Pakistani women aged 20 to 45 years with mean \pm SD was $35.6 \pm 7.4$ years (6). The status of BMD at lumbar spine and femur were depicted in Figure $1 \& 2$. At lumbar spine, out of 180 women majority of them had normal bone mass but at femur greater percentage of women had low BMD. In a very recent study low BMD was about $46 \%$ at lumbar spine and $61 \%$ at femur which was very much similar to the present study (7). As Bangladesh and India both are developing countries so that the socioeconomic status is almost similar in these two countries. Evaluated findings had similarity may be due to similar background.

Bivariate analysis between age group and BMD represented that in case of lumbar spine, $52.8 \%(\mathrm{n}=37)$ of low BMD was observed in older age group $(\geq 39$ 
years of age) and in case of femur, low BMD were observed in $77.1 \%(n=37)$ in women of 39 years and above. These differences of BMD values between younger and older age group were statistically significant $(\mathrm{P}<0.05)$. Similar findings were found by Matsushita et al. (2000) where age was significantly associated with BMD $(\mathrm{p}<0.05)(8)$. T-scores of BMD were negatively correlated with maternal age at the subsequent deliveries indicating that the percentage decrease in BMD was greater for the older women at subsequent delivery.

In the present study (Table 3) it was found that there was significant association between parity and BMD at lumbar spine and femoral neck $(\mathrm{p}<0.001)$. T-scores of BMD were decreased with increasing number of parities. The primary cause for this disruption may be due to the calcium requirement of the rapidly mineralizing skeleton of the fetus and neonate. These findings were consistent with those by Fatima et al. (2009) who found that increasing number of parity was significantly associated with decreasing $\mathrm{BMD}(\mathrm{P}<0.001)$ (6). The findings were similar to a recent study conducted in India suggesting that the percentage of developing low bone mass were significantly higher in multiparous than in primiparous women $(\mathrm{p}<0.05)(9)$.

The most significant limitation of this study was the small number of women with limited study period and it was a nonrandomized sampling method. Another limitation of this study was that no baseline BMD values of study subjects available to which the current status could be compared.

Disclosure of conflict of interest: The authors declare that there is no conflict of interests regarding the publication of this paper.

Acknowledgments: This article is the partial work of M-Phil thesis of first author obtained from NINMAS, 2013. This research work was approved and funded by Academic Committee of the NINMAS. We are sincerely grateful to authority of NINMAS for funding and support for the study.

\section{CONCLUSION}

This cross-sectional study provides some important information on the relationship between BMD and parity in women of reproductive age group. The findings of this study among 180 women revealed that BMD at lumbar spine and femur was negatively associated with parity. It was observed that the values of BMD in nulliparous women and one-to-two parity groups were significantly higher than multiparous women. From overall analysis of the present study, it may be concluded that values of BMD decreased with increasing number of parity.

\section{REFERENCES}

1. Young JWR. Metabolic and Endocrine Disorders Affecting Bone. In: Sutton D, Robinson PJA, Jenkins JPR, Whitehouse RW, Allan PL, Wilde P and Stevens JM, editors. Textbook of Radiology and Imaging. 7th ed. Churchill Livingstone, PA: Elsevier, 2003; 1351-52.

2. Dutta DC. In: H Konner, editor. Textbook of Obstetrics. 7th ed. Kolkata, New Central Book Agency (P) Limited, 2011.

3. Handa R Kalla AA and Maalouf G. Osteoporosis in Developing Countries. Best Pract Res Clin Rheum 2008; 22(4): 693-708.

4. Kojima N, Douchi T, Kosha S and Nagata Y. Crosssectional Study of the Effects of Parturition and Lactation on Bone Mineral Density Later in Life. Maturitus, Europian J Menopause 2002; 41: 203-09.

5. Norland. Operator's guide. Cooper Surgical Company 2001 USA, Model: XR-46, viewed 22 February 2013, www. norland. com

6. Fatima M, Nawaz H, Kassi M, Rehman R, Kasi PM, Kassi M et al. Determining the Risk Factors and Prevalence of Osteoporosis using Quantitative Ultrasonography in Pakistani Adult Women. Singapore J Medical 2009; 50(1): 20-27.

7. Soniya M, Ashok K, Gupta RK, Sanjana K, Gulati P and Shukla DK. Comparison of Bone Mineral Density and its Variables between Premenopausal and Postmenopausal Women. J Obs and Gyn of India 2011; 200-04.

8. Matsushita H, Kurabbayashi T, Tomita M, Honda A, Takakuwa $\mathrm{K}$ and Tanaka K. The Effects of Multiple Pregnancies on Lumbar Bone Mineral Density in Japanese Women. Calc Tissue Int 2002; 71: 10-13.

9. Priti K, Chandravati and Khattar R. Bone Morbidity in Pregnant Women. J Obs and Gyn of India 2005; 55(5): 43435. 